The Bangladesh Veterinarian (2012) 29(1) : 1 - 6

\title{
Arsenic in rice and rice straw
}

S. Chakma, M. M. Rahman*, P. Islam, M. A. Awal, U. K. Roy and M. R. Haq

Department of Pharmacology, Faculty of Veterinary Science, Bangladesh Agricultural University, Mymensingh-2202, Bangladesh

\begin{abstract}
Arsenic from groundwater affects people in Bangladesh via seed grains and forages. Samples of rice (Oryza sativa L) and rice straw were collected from arsenic-contaminated areas and arsenic concentration was measured using Flow Injection Hidride Generator Atomic Absorption Spectrophotometer (FI-HG-AAS) method. The concentrations in rice and rice straw were $0.235 \pm 0.014 \mathrm{ppm}(\mathrm{n}=48)$ and $1.149 \pm 0.119 \mathrm{ppm}(\mathrm{n}=51)$, respectively. Both were greater than the maximum permissible concentration in drinking water (0.05 ppm; WHO). (Bangl. vet. 2012. Vol. 29, No. 1, 1 - 6)
\end{abstract}

\section{Introduction}

Arsenic ranked the first in a list of 20 hazardous substances by the Agency for Toxic Substances and Disease Registry (Goering et al., 1999). Higher arsenic concentrations have been reported in the top layer of soil (Huq et al., 2003). The main source of air and soil contamination with arsenic compounds is the mining of coal and oil as well as mining and metallurgy of non-ferrous metals (Ozna and Biernat, 2008) and in drinking water the source is arsenic-rich rocks through which the water has filtered. The use of groundwater for irrigation has increased greatly over the last couple of decades. About $80 \%$ of pumped groundwater is utilized for crops, but the groundwater in many areas of Bangladesh is severely contaminated with arsenic. There is a possibility of arsenic accumulation in rice and rice plants from irrigation water (Delowar et al., 2005). Arsenic-rich groundwater from shallow tubewells is widely used for the irrigation of Boro rice in Bangladesh (Dittmar et al., 2007). Arsenic is transported by the blood to different organs in the body, mainly in the form of monomethylarsonic acid. After acute and chronic exposure arsenic causes a wide variety of adverse health effects to humans (Mandal and Suzuki, 2002).

Ghosh (2011) reported that 83.3\% cows in Bangladesh depended on shallow tubewell water for drinking and arsenic is also deposited into cattle body through rice straw and husk, which in turn finds a route into the human body. Arsenic intake in humans from rice and cattle could be potentially hazardous as the people of the contaminated areas are also getting arsenic from drinking water (Rahman et al., 2008). Feeding cattle with contaminated straw could be a threat to their health and indirectly to human health via contaminated beef and milk (Abedin et al., 2002). The present

*Corresponding author:- E-mail: mahmud_ubc@yahoo.ca 
study was conducted to estimate the concentration of arsenic in rice and rice straw collected from selected areas of Daudkandi Upazilla (sub-district) of Comilla district of Bangladesh.

\section{Materials and Methods}

The rice and its straw were collected from six unions (North Eliotganj, South Eliotgonj, North Mohammadpur, South Mohammadpur, East Mohammadpur, West Mohammadpur) in Daudkandi Upazilla of Comilla district and that has been identified as one of the most contaminated areas (DPHE-BGS, 2000).

\section{Sample preparation and digestion}

Rice: Rice samples were sun-dried. About 0.95 -1g samples were taken separately into digestion tube and $10 \mathrm{~mL}$ of $69 \%$ concentrated nitric acid and $70 \%$ of perchloric acid mixture at the ratio of 5:3 was added. The samples were left to react overnight in a chemical hood, then heated in a block digester (M-24 plazas/samples, JP Selecta, Spain) at $120^{\circ} \mathrm{C}$ until colourless clear watery fluid appeared. Tubes were gently shaken several times to facilitate destroying all the carbonaceous material. This digestion converts all arsenicals to inorganic arsenic for FI-HG-AAS determination. Tubes were removed from the digestion block, cooled, diluted to $50 \mathrm{~mL}$ adding Millipore water, filtered through filter paper and stored in $50 \mathrm{~mL}$ plastic bottles.

Rice straw: Clean and oven-dried samples were digested as described by Wang et al. (2006) with modifications. About $0.45-0.50 \mathrm{~g}$ rice straw was weighed after further drying at $60^{\circ} \mathrm{C}$ to constant weight. It was taken separately into digestion tube and $7 \mathrm{~mL}$ of $69 \%$ concentrated nitric acid was added and similar procedures were followed as before.

\section{Detection of Arsenic}

Concentrations of arsenic in digested samples were determined using atomic absorption spectrophotometer (AAS), model PG - 990 equipped with a computer with atomic absorption (AA) Win software (PG Instruments Ltd., UK) as described by Samanta et al. (1999). Briefly, samples were spiked with standards at different concentrations. For constructing standard curve, working standards of $0,2.5,5,10,15$ and $20 \mathrm{ppb}$ were prepared immediately before use by serial dilution of the stock in $10 \%$ hydrochloric acid. Samples exceeding the standard curve range were diluted again and analysed further. The concentration of arsenic in those samples was calculated by multiplying the appropriate dilution factor. Sample solution concentrations were determined by direct comparison with the calibration curve and the reading was automatically transferred to AA Win software. Concentration of arsenic in the sample was calculated from the following formula:

Arsenic concentration $(\mathrm{ppm})=\frac{\text { Concentration of arsenic in sample solution }(\mu \mathrm{L}) \times \mathrm{mL} \text { of sample }}{\text { Sample weight }(\mathrm{g}) \times 1000}$ 
Statistical analysis

The data were analysed statistically using Student's $t$-test as described by Bailey (1981).

\section{Results and Discussion}

The concentration of arsenic in rice ranged from 0.04605 to $0.46981 \mathrm{ppm}$ with a mean $( \pm$ SEM) value of $0.235 \pm 0.014 \mathrm{ppm}(\mathrm{n}=48$; Table 1$)$. Arsenic concentration in rice straw was significantly higher $(\mathrm{P}<0.01)$ than in rice (Fig. 1$)$, ranging from 0.077 to $5.139 \mathrm{ppm}$ with a mean $( \pm$ SEM $)$ value of $1.149 \pm 0.119 \mathrm{ppm}(\mathrm{n}=51)$. Similar concentration of arsenic in rice $(0.213 \pm 0.125, \mathrm{n}=35)$ from the same area was reported by Haq (2012).

Table 1. Concentration of arsenic (ppm) in rice and rice straw collected from contaminated areas of Comilla district

\begin{tabular}{c|c|c|c|c}
\hline Sample Name & Mean (Range) & SD & SEM & $\mathrm{n}$ \\
\hline Rice & 0.235424 & 0.099039 & 0.014295 & 48 \\
& $(0.04605-0.46981)$ & & & \\
Rice straw & 1.149421 & 0.855987 & 0.119862 & 51 \\
& $(0.077-5.139)$ & & & \\
\hline
\end{tabular}

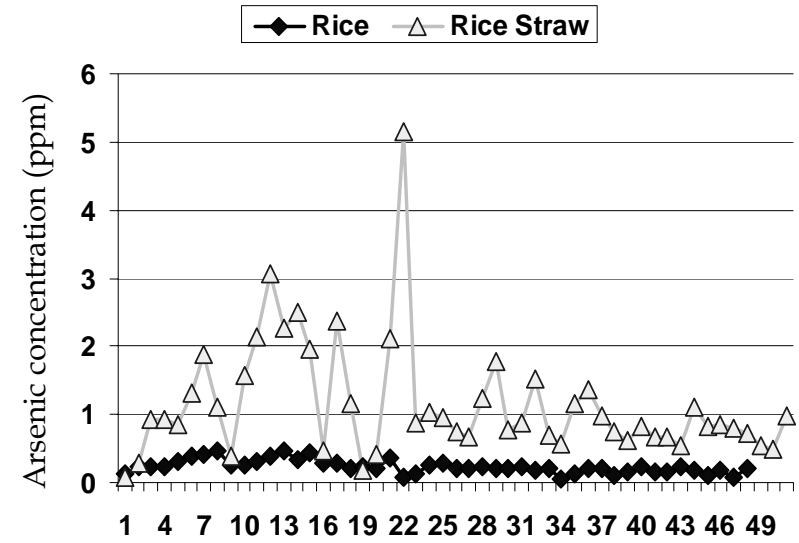

Sample numbers

Fig. 1. Arsenic concentration (ppm) in rice and rice straw collected from arsenic-contaminated areas of Comilla district

The concentrations of arsenic in rice straw varied more than in rice (Fig. 1). The fluctuations could be due to differences in the absorption and distribution of arsenic in the plant. Moreover, the root of the rice plant accumulates higher concentrations of arsenic than other parts of the mature plant. Rahman et al. (2007) found significantly higher concentration of as in different parts of various rice varieties in the order: straw $>$ husk $>$ brown rice grain $>$ polished rice grain. Another reason for variation in the 
concentration of arsenic in rice straw could be variation in the soil arsenic concentration, which is supported by a study carried out in Mymensingh district of Bangladesh where the arsenic concentration in soil varied considerably between locations (Islam et al., 2004).

A research group based at Cornell University reported that average arsenic concentrations in Brahmanbaria district of Bangladesh in rice grain and rice straw were 0.45 and $2.00 \mathrm{ppm}$, respectively (Farid et al., 2005). These figures are approximately double what were found in this study. These variations could be due to differences in soil and water arsenic concentrations in different districts of Bangladesh. The Cornell group found significant correlations between arsenic contents of soil, grain and straw (Farid et al., 2005).

In Thailand concentrations of inorganic arsenic in polished white, jasmine and sticky rice were $0.068 \pm 17.6,0.068 \pm 15.6$, and $0.075 \pm 24.8 \mathrm{ppm}$, respectively, while those in three brown rice samples were $0.124 \pm 34.4,0.120 \pm 31.6$, and $0.131 \pm 35.6$ ppm, respectively (Ruangwises et al., 2012). Arsenic concentration in brown rice is greater than in polished rice. However, the concentration of arsenic in Thai rice is almost half that found in rice from Comilla district of Bangladesh.

There was no significant difference between rice varieties. The average concentration of arsenic in the Aman variety of rice was $0.192 \pm 0.026$ and that in Boro was $0.242 \pm 0.016 \mathrm{ppm}$. There were significant differences in the concentration of arsenic in rice straw of different varieties (Hossain et al., 2008). The values for Aus (cultivated April to August), Aman (cultivated July to December) and Boro (cultivated November to July) straw were $702.4 \pm 67.1 \mathrm{ppb}(95 \% \mathrm{CI}: 559.5-845.3 \mathrm{ppb})$, $431.7 \pm 28.8 \mathrm{ppb}(95 \% \mathrm{CI}: 374.0-489.5 \mathrm{ppb})$ and $1386.9 \pm 71.8 \mathrm{ppb}(95 \% \mathrm{CI}: 1245.1-$ $1528.8 \mathrm{ppb})$, respectively. Content of arsenic in Boro straw was significantly $(\mathrm{P}<0.01)$ higher than that in Aus and Aman straw, whereas no significant $(\mathrm{P}>0.05)$ difference was found between Aus and Aman straw (Ghosh, 2011).

Because, shallow tubewell water is considered to be the primary source of contamination of irrigated crops, the concentration of arsenic in shallow tubewell water was compared with the concentrations in rice and rice straw of Daudkandi Upazilla of Comilla district. In Daudkandi Upazilla, the mean arsenic concentration in shallow tubewell water is 0.455 ppm (93 - 183 feet, 28 - 56 metres depth), 10 times higher than the Bangladesh maximum permissible limit of 0.05 ppm (Das et al., 2002).

In this study rice and rice straw were collected from Daudkandi Upazilla of Comilla district and the average concentrations of arsenic were $0.235 \pm 0.014$ and 1.149 $\pm 0.119 \mathrm{ppm}$, respectively. The rice plant accumulated more arsenic than rice and the latter accumulated less arsenic than in the shallow tubewell water of the same area.

\section{Conclusions}

The concentrations of arsenic in rice grain $(0.235 \pm 0.014 \mathrm{ppm})$ and straw $(1.149 \pm$ $0.119 \mathrm{ppm}$ ) is four and 22 times greater than the maximum permissible concentration 
of arsenic in drinking water (0.05 ppm, WHO), respectively. The grain contains less arsenic than the straw. Since, many animals are mainly fed on rice straw, this is an alarming concentration of arsenic. Arsenic tolerance could be due to detoxification in some plant species (Mallick et al., 2011). Cultivation of arsenic-accumulating plants can be followed by cultivation of rice or other grains. Cucumis sativus (cucumber) has been found to be the best for extraction of arsenic from soil and water (Hong et al., 2011).

\section{Acknowledgement}

The authors are thankful to the Cornell University, USA for financial assistance.

\section{References}

Abedin MDJ, Cotter HJ, Meharg AA 2002: Arsenic uptake and accumulation in rice (Oryza sativa L.) irrigated with contaminated water. Plant and Soil 240 311-319.

Bailey NTZ 1981: The use of $t$-test for small samples. Statistical Methods in Biology, $2^{\text {nd }}$ edn, Hodder and Stoughton, Great Britain.

Das HK, Chowdhury DA, Rahman S, Obaidullah, Miah MU, Sengupta P, Islam F 2002: Arsenic contamination of soil and water and related bio-hazards in Bangladesh. Environment International 30 383-387.

Delowar HKM, Yoshida I, Harada M, Uddin MI 2005: Effect of arsenic-contaminated water on food chain in Bangladesh: analysis of arsenic in soil, water and plants. Journal of Food, Agriculture and Environment 3 282-286.

Dittmar J, Voegelin A, Roberts LC, Hug SJ, Saha GC, Ali MA, Badruzzaman ABM, Kretzschmar R 2007: Spatial distribution and temporal variability of arsenic in irrigated rice fields in Bangladesh. Paddy soil: Environmental Science and Technology $\mathbf{4 1}$ 5967-5972.

DPHE-BGS 2000: Groundwater studies for arsenic contamination in Bangladesh. Department of Public Health and Engineering and British Geological Survey, pp. 11-19.

Farid ATM, Haque MA, Duxbury J 2005: Arsenic status of water, soil rice grain and straw at individual shallow tubewell selected area of Brahmanbaria. Division of Soil Science, Bangladesh Agriculture Research Institute, Gazipur, Bangladesh, Cornell University, USA.

Ghosh A 2011: Quantitative measurement of arsenic and its prevention in experimental toxicity in goats. PhD Thesis, Department of Pharmacology, Faculty of Veterinary Science, Bangladesh Agricultural University, Mymensingh, Bangladesh.

Goering PL, Aposhia HV, Mass MJ, Cebrian M, Beck BD, Waalkes MP 1999: The enigma of arsenic carcinogenesis: Role of metabolism. Toxicological Science 49 5-14.

Haq MR 2012: Detection of arsenic in animal feed chain: broken rice and water hyacinth. MS Thesis, Department of Pharmacology, Faculty of Veterinary Science, Bangladesh Agricultural University, Bangladesh Agricultural University, Mymensingh, Bangladesh. 
Hong SH, Choi SA, Yoon H, Cho KS 2011: Screening of Cucumis sativus as a new arsenicaccumulating plant and its arsenic accumulation in hydroponic culture. Environment, Geochemical and Health (33-Suppl) 1 143-149.

Hossain M, Islam MR, Jahiruddin M, Abedin A, Islam S, Meharg AA 2008: Effects of arsenic-contaminated irrigation water on growth, yield, and nutrient concentration in rice. Communications in Soil Science and Plant Analysis 39 302-313.

Huq MA, Parveen F, Chodury SR 2003: A cheap and convenient modification of arsenic generator used for arsenic generation. Mymensingh Medical Journal 12 30-32.

Islam MR, Jahiruddin M, Islam S 2004: Assessment of arsenic in the water-soil-plant systems in Gangetic floodplains of Bangladesh. Asian Journal of Plant Sciences 3 489-493.

Karim MA 1999: Study on the effect of spirulina in the treatment of chronic arsenicosis in Bangladesh population. $1^{\text {st }}$ International Conference of Dermatology Monograph, Dhaka, Bangladesh, May 8-10, Article No. 13.

Mallick S, Sinam G, Sinha S 2011: Study on arsenate tolerant and sensitive cultivars of Zea mays L.: differential detoxification mechanism and effect on nutrients status. Ecotoxicology and Environmental Science 74 1316-1324.

Mandal BK and Suzuki KT 2002: Arsenic round the world: A review. Talanta 58 201-235.

Ozna K, Biernat J 2008: The occurrence of arsenic in the environment and food. Roczniki Panstwowego Zakadu Higieny 59 19-31.

Rahman MA, Hasegawa H, Rahman MM, Islam MN, Miah MAM, Tasmen A 2007: Effect of arsenic on photosynthesis, growth and yield of five widely cultivated rice (Oryza sativa L.) varieties in Bangladesh. Chemosphere 67 1072-1079.

Rahman MA, Hasegawa H, Rahman MM, Miah MAM, Tasmin A 2008: Straighthead disease of rice (Oryza sativa L.) induced by arsenic toxicity, Environmental and Experimental Botany 62 54-59.

Ruangwises S, Saipan P, Tengiaroenkui B, Ruangwises N 2012: Total and inorganic arsenic in rice and rice bran purchased in Thailand. Journal of Food Protection 75 771-774.

Samanta G, Chowdhury TR, Mandal BK, Biswas BK, Chowdhury UK, Basu GK, Chanda C, Lodh RD, Chakraborti D 1999: Flow injection hydride generation atomic absorption spectrometry for determination of arsenic in water and biological samples from arsenic affected districts of West Bengal, India, and Bangladesh. Microchemical Journal 62 174-191.

Wang FM, Chen ZL, Zhang L, Gao L, Sun YX 2006: Arsenic uptake and accumulation in rice (Oryza sativa L.) at different growth stages following soil incorporation of roxarsone and arsanilic acid. Plant and Soil 285 359-367.

WHO 2001: Arsenic and Arsenic Compounds. $2^{\text {nd }}$ edn, Environmental Health Criteria, World Health Organization, 224 Geneva, Switzerland. 